\title{
Forecasting the coal industry development the in Russia in the context of the transition to carbon neutrality
}

\author{
Aleksandr Prosekov, and Artem Rada* \\ Kemerovo State University, 650000 Krasnaja ulica 6, Kemerovo, Russia
}

\begin{abstract}
The purpose of the study is to develop a forecast for the development of the coal industry in Russia for 2021-2030 in the context of the transition to carbon neutrality. Irwin's criterion was used to analyze outliers of a number of dynamics, the method of ascending and descending series to identify a trend, standard methods for assessing autocorrelation and heteroscedasticity. For forecasting, the equations of trends, the method of exponential smoothing were used. The necessity of constructing a differentiated forecast for three elements of the use of coal mined in Russia is shown: domestic consumption, export to Europe, export to the AsiaPacific region. Domestic coal consumption is very stable and with a $95 \%$ probability it will be between 210 and 225 million tons. Coal exports to the west will decline monotonically in line with plans by European governments to stop using thermal coal. It will be about 60 million tons in 2025 and about 15-20 million tons in 2030. Exports to the countries of the Asia-Pacific region will grow until 2030. After 2030, demand for thermal coal in the Asia-Pacific region will begin to decline in line with China's plans to move towards carbon neutrality by 2050-2060. According to the forecast obtained in the study, the export of coal from Russia to the east will reach 150 million tons in 2025 and 190 million tons in 2030, after which it will begin to decline. Therefore, the coal-mining regions of Russia in the next 5-10 years must diversify the economy.
\end{abstract}

\section{Introduction}

The conclusion and ratification of the Paris Climate Agreement in 2015-2016, and other initiatives for the transition of the global economy to carbon neutrality pose significant risks for many countries with significant volumes of coal production and export, such as Russia [1]. Even among fossil fuels, which are sharply criticized for their greenhouse gas emissions, coal is considered the dirtiest compared to, for example, natural gas [2]. Therefore, the coal industry will undergo the most dramatic transformation if plans for carbon neutrality are implemented.

It is assumed that restrictions on greenhouse gas emissions, carbon emissions will lead to a significant decrease in the volume of work and profits of the coal industry. This, in

\footnotetext{
*Corresponding author: rada.ao@kemsu.ru
} 
turn, will negatively affect the situation in a number of regions of Russia, such as the Kemerovo region - Kuzbass or the Republic of Buryatia, where the coal industry occupies a significant share in employment, investment and tax collections [3]. Indeed, reducing carbon dioxide emissions to zero requires drastic reductions in coal combustion. Therefore, it is possible to predict a rapid monotonous decline in coal production in Russia.

On the other hand, not all countries that have signed the Paris Agreements strive for carbon neutrality. As D. Lugo-Morin notes, "The possibility of transitioning to a decarbonized global economy or zero carbon emissions is not encouraging" [4]. The largest greenhouse gas emitters (China, United States, Russia, Saudi Arabia, Canada, Iran, India, Australia, Indonesia, and Brazil) have varying degrees of business and government interest in the transition to a low-carbon economy.

Some national elites are skeptical about the possibility of reducing greenhouse gas emissions and the reality of global warming due to human activities. States such as Saudi Arabia, Indonesia or Iran also do not have an objective opportunity to drastically reduce the production and (or) export of fossil fuels. This will lead to an acute financial and economic and further socio-political crisis.

Further, the Paris Agreement (like the earlier Kyoto Protocol) is a declaration of interest, and not legally significant obligations with sanctions for non-performance. Practice shows that climate agreements can be ignored by many countries that continue "doing business as usual". Failure to fulfill obligations entails only moral responsibility. Therefore, many states can ignore the Paris Agreement and continue to invest in fossil fuel production, in particular in the coal industry.

Therefore, forecasting the development of the coal industry in Russia and its regions seems to be a complex non-standard task. It is necessary to assess the existing trends, highlight the main factors affecting production rates, and develop scenarios that will determine the future of the industry. It should be noted that the prospects of the coal industry as a whole, especially at the level of individual national economies, have not been sufficiently studied. The expected decline in production volumes is postulated in most works, but specific values, as well as regional differentiation, require further research.

In a study by $\mathrm{M}$ Jakob et al. it is noted that it is necessary to end the use of coal, which does not capture and store carbon, by 2050, but this is extremely difficult to do. While the USA, Canada and European countries are reducing production, in the Asia-Pacific region it is growing. In the future, active coal mining may start in African countries [5]. Therefore, forecasting world production without differentiation by country does not make sense. Developed countries, as you know, propose to stop mining and use of coal by 2040-2050, but developing countries may have a different position.

D. Jie, X. Xu, F. Gao forecast the dynamics of coal production in China, according to two scenarios. In the first "business as usual" scenario, production will peak in 2030. In GREEN and carbon price scenarios, production peak has already been reached. China's implementation of the Paris Agreement requires an immediate production cut. In addition, a significant increase in coal hydrogenation is expected (221 million tons of coal will be processed into liquid fuel in 2050, compared to 11 million tons in 2015) [6].

In provinces such as Shanxi, where coal mines provide $46 \%$ of tax revenues and $29 \%$ of GDP, the transition to zero emissions is generally difficult to achieve without extreme measures that require the allocation of large resources [7]. However, in any country, the transition to a low-carbon or no-carbon economy leads to a net loss of jobs and GDP, which burden the costs, associated with rising energy costs [8]. It also makes it necessary to retain part of the national coal industry.

When assessing the forecast volumes of coal production, it should be borne in mind that energy production is an important, but not the only direction of its use. Most scenarios for reducing greenhouse gas emissions assume either reaching a maximum of coal-fired 
generation by 2030 with a subsequent decrease, or a monotonous decrease from 2020-2021 to almost zero by 2050 [9]. But part of the coal will remain irreplaceable as a source of coke (it is currently impossible to replace it), a chemical raw material. Also, coal will retain its importance as a boiler and furnace fuel where it is impossible or very expensive to use natural gas or renewable energy sources.

For Russia, the dynamics and prospects of coal mining in the existing works are insufficiently studied and require further research. H. Xiao et al. note that Russia has made some progress in reducing greenhouse gas emissions from coal. Their share in total emissions decreased from $22.66 \%$ in 2005 to $15.57 \%$ in 2019 [10]. This can be explained by the intensification of coal exports with a simultaneous decrease in national consumption.

Russian scientists believe that, according to the optimistic scenario, coal production in Russia in 2035 will amount to 330 to 365 million tons, of which 145 to 170 million tons will be exported ( $44 \%$ to $47 \%$ ). At the same time, government documents on the development of the coal industry contain a figure from 485 million tons to 670 million tons, which experts consider unrealistic [11].

The dynamics of coal production in Russia will seriously depend on the situation in the Kuznetsk coal basin (Kemerovo region - Kuzbass). Its competitive advantage is the high quality and variety of coal grades (whiles the Kuznetsk coals, when burned, emit less than average greenhouse gases). At the same time, the main problem in export is the long distance of delivery by rail [12]. According to some researchers and experts, Russia will follow Asian rather than European and American trends in coal mining [13, 14]. The Russian coal industry will increase its exports to the huge market in the Asia-Pacific region, where population, economic activity and demand for energy resources are growing.

According to the authors, the dynamics of coal production in Russia cannot be predicted by extrapolation due to the influence of exogenous shocks. In the medium term, for example 5-10 years, price shocks are possible and institutional decisions to decrease or increase coal productions are possible. It is also important to take into account the structure of coal use (within the country, for export), the regional proportions of its production. Therefore, the purpose of the article is to develop a forecast for the development of the coal industry in Russia, taking into account the structure of coal production and consumption.

\section{Research methodologies}

In the study the authors proceeded from the hypothesis that the dynamics of coal production in Russia will depend on several factors. Firstly, these are the needs of the national economy (energy, metallurgical industry), which are quite stable. They change depending on how cold or mild the winter will be in Russia, as well as on how much products metallurgy plans to produce. Secondly, a significant part of coal from Russia is exported. The dynamics of exports depends on demand and prices in the external market. Therefore, it is advisable to analyze these two components of coal mining separately. The analysis was carried out for the period 2000-2020, the forecast was based on the period up to 2030 .

The study used quantitative data characterizing the dynamics and structure of coal production and use in Russia. These data are published by national authorities (Federal State Statistics Service of Russia, Ministry of Energy of Russia), as well as by BP. These data were processed by standard methods of statistical analysis, including regression analysis, selection and construction of trend equations with an assessment of statistical significance using the Student and Fisher criteria, Brown's method for exponential smoothing of time series, Irwin's test for searching for anomalous values, the method of descending and ascending series for identifying a trend. The calculations were performed at 
the Center for Shared Use of Scientific Equipment at Kemerovo State University (Kemerovo, Russia).

\section{Research results}

Table 1 presents data on the dynamics of coal production in Russia. They are obtained from three sources - the Federal State Statistics Service of Russia, the Ministry of Energy of Russia and the "BP".

Table 1. Dynamics of coal production in Russia according to various estimates, million tons.

\begin{tabular}{|c|c|c|c|}
\hline & Federal State Statistics Service of Russia & Ministry of Energy of Russia & "BP”' \\
\hline 2000 & 258 & No data & 262 \\
\hline 2001 & 270 & No data & 274 \\
\hline 2002 & 256 & No data & 259 \\
\hline 2003 & 277 & No data & 279 \\
\hline 2004 & 282 & No data & 285 \\
\hline 2005 & 299 & No data & 300 \\
\hline 2006 & 310 & No data & 311 \\
\hline 2007 & 314 & No data & 316 \\
\hline 2008 & 329 & No data & 330 \\
\hline 2009 & 301 & No data & 303 \\
\hline 2010 & 322 & No data & 323 \\
\hline 2011 & 336 & 337 & 337 \\
\hline 2012 & 357 & 355 & 358 \\
\hline 2013 & 353 & 352 & 355 \\
\hline 2014 & 357 & 359 & 357 \\
\hline 2015 & 372 & 374 & 373 \\
\hline 2016 & 386 & 386 & 387 \\
\hline 2017 & 410 & 411 & 413 \\
\hline 2018 & 439 & 439 & 442 \\
\hline 2019 & 439 & 441 & 441 \\
\hline 2020 & 398 & 402 & 400 \\
\hline
\end{tabular}


As you can see from the data provided, information from different sources may differ. For example, for 2020 the spread of estimates is about 4 million tons, or about $1 \%$. In most cases, national sources give a more conservative estimate of production than BP data. However, for the purposes of identifying trends, such discrepancies are not critical. The research will mainly use data from Federal State Statistics Service of Russia.

Let us consider the characteristics of a number of dynamics reflecting coal production in Russia in 2000-2020. In general, over the period under study, this figure increased by 140 million tons, or $54.3 \%$. If we exclude 2020 and a sharp economic downturn due to exogenous shocks from consideration, then in 2018-2019 coal production in Russia increased by more than $70 \%$. The growth was almost monotonous, even the 2009 crisis did not lead to a significant and long-term decline in production. The Russian coal industry has used its competitive advantages to significantly boost exports. On average, coal production grew by $2.2 \%$ annually, or 7 million tons.

A number of dynamics were tested for the presence of abnormal values using the Irwin test (significance level 5\%). As a result, no abnormal values were detected (the threshold value for all years does not exceed the critical value for 21 degrees of freedom $\lambda=1.2$ ). At the same time, autocorrelation is partially observed.

The linear first-order autocorrelation coefficient, usually estimated on the Chaddock scale, is 0.949 . The coefficient is significant according to the Student's test: the F-statistic was 17.83 at the $5 \%$ significance level (the critical value for 18 degrees of freedom is 2.45 ). There is no second order autocorrelation. Consequently, the series under study has a definite tendency, as it can be assumed, an upward trend. The presence of a trend was assessed using the descending series method. Calculations have shown that the hypothesis of a trend should be accepted.

However, it is rather difficult to determine its shape. Thus, the linear equation showing the expected increase by 8.7 million tons per year is statistically significant according to Fisher's and Student's criteria (equation form and coefficients), the approximation error is very low (less than 3.5\%). But the observed first-order autocorrelation does not guarantee the correctness of the linear trend and the possibility of its use for forecasting.

Calculations show that polynomials of the second and even higher orders are statistically significant and more correct. From an economic point of view, indeed, coal production in Russia grew at an accelerated rate during certain periods, and then, under the influence of external shocks, fell sharply. Significant falls were observed in 2002, 2009 and 2020 , which can be considered inflection points. But observations are not enough to construct equations of this form, so the possibility of forecasting from them is doubtful. Table 2 shows the forecast of coal production $Y$, obtained using a hyperbolic equation that takes into account only the time factor $\mathrm{t}$. It has the form $Y=-3510700 / t+17824$.

Table 2. Forecast of coal production in Russia according to the hyperbolic trend equation for 20212030 , million tons.

\begin{tabular}{|c|c|c|c|c|c|c|c|c|c|c|}
\hline $\mathbf{2 0 2 0}$ & $\mathbf{2 0 2 1}$ & $\mathbf{2 0 2 2}$ & $\mathbf{2 0 2 3}$ & $\mathbf{2 0 2 4}$ & $\mathbf{2 0 2 5}$ & $\mathbf{2 0 2 6}$ & $\mathbf{2 0 2 7}$ & $\mathbf{2 0 2 8}$ & $\mathbf{2 0 2 9}$ & $\mathbf{2 0 3 0}$ \\
\hline 398 & 409 & 414 & 419 & 425 & 431 & 437 & 444 & 451 & 458 & 466 \\
\hline
\end{tabular}

The estimated production for 2030 at 466 million tons is almost 100 million tons higher than the estimate obtained in [11]. At the same time, it is close to the lower limit of government plans for coal production in the country (they were mentioned above). At the same time, the forecast, due to the insufficient number of observation periods for constructing the parabola, does not take into account the inevitable decline in production in certain years. At the same time, the forecast for recovery of production in 2021 is 
underestimated. According to preliminary estimates, coal production in Russia increased by $8-9 \%$ in the first 9 months of 2021, while less than $3 \%$ was predicted.

The hyperbolic trend equation, due to an insufficient number of observations, does not allow obtaining inflection points. This reduces the value of the forecast. Thus, the results of the study show the need for differentiated forecasting of different components of production, as well as the use of methods for smoothing the time series.

\section{The discussion of the results}

The results of the study showed that the complexity of the dynamics of the coal mining process in Russia cannot be reliably predicted by extrapolating the trend equations. This is due to the lack of information for constructing polynomials of the second and higher orders. In this regard, at the next stage of the study, the possibility of forecasting using exponential smoothing methods was considered. This technique allows you to reduce the impact of external shocks (emissions) on the long-term forecast. Figure 1 shows the actual and exponentially smoothed indicators of coal production in Russia. For better clarity, data are given for 2006-2020.

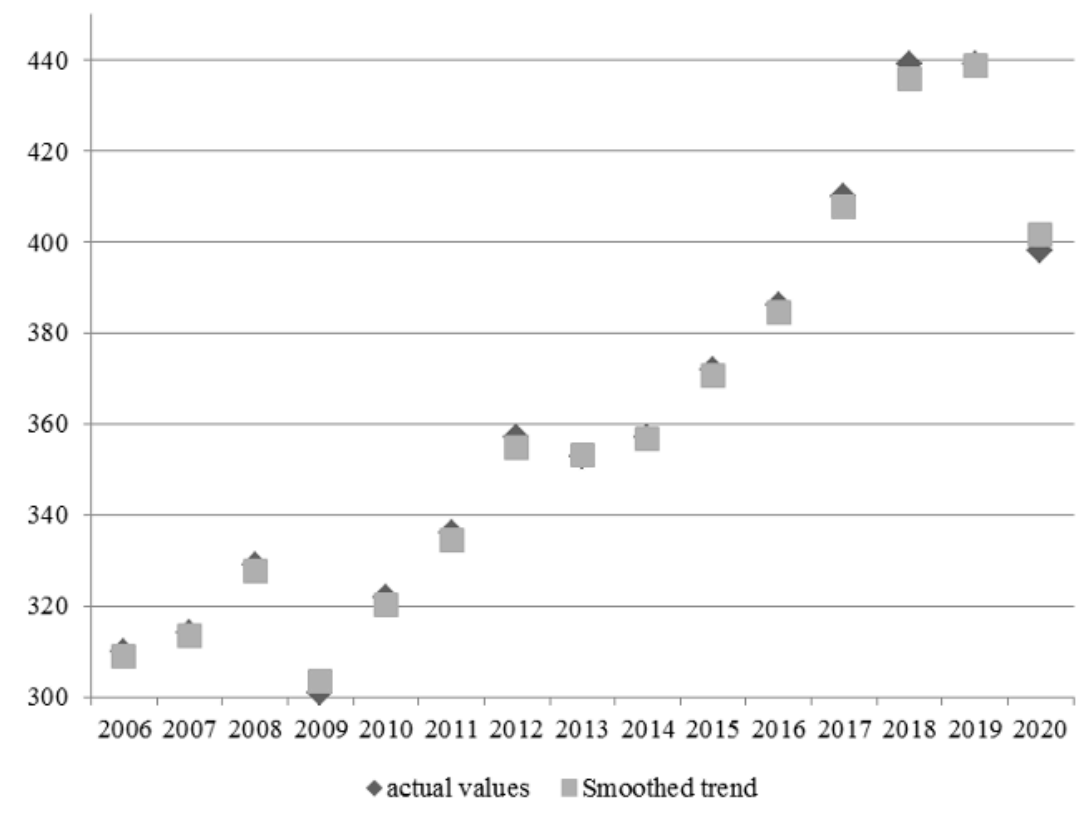

Fig. 1. Exponential smoothing of coal production in Russia, 2006-2020.

The standard error (forecast error) was 1.71, which indicates a sufficiently high accuracy of the selection of the method for aligning the time series. However, when predicting the production volume for 2021 using the basic equation, the following estimate was obtained: $S(2021+1)=401.7(1-0.0909)+0.0909 \times 398=401.4$ million tons. This is an even more underestimated value than that which was obtained using the hyperbola equation. It does not allow taking into account the effect of the post-crisis recovery of production.

Consequently, the study confirmed the hypothesis that it is impractical to predict the total volume of coal production in Russia. Domestic consumption and export obey different patterns. Table 3 shows the distribution of mined coal for domestic consumption and exports. 
Table 3. The ratio of export and domestic consumption of coal mined in Russia.

\begin{tabular}{|c|c|c|c|c|}
\hline & \multicolumn{2}{|c|}{ Domestic consumption } & \multicolumn{2}{c|}{ Export supplies } \\
\cline { 2 - 5 } & Million tons & Percent & Million tons & Percent \\
\hline 2001 & 228 & 84.6 & 42 & 15.4 \\
\hline 2002 & 213 & 83.1 & 43 & 16.9 \\
\hline 2003 & 216 & 78.1 & 61 & 21.9 \\
\hline 2004 & 210 & 74.4 & 72 & 25.6 \\
\hline 2005 & 219 & 73.2 & 80 & 26.8 \\
\hline 2006 & 218 & 70.4 & 92 & 29.6 \\
\hline 2007 & 215 & 68.6 & 99 & 31.4 \\
\hline 2008 & 231 & 70.2 & 98 & 29.8 \\
\hline 2009 & 195 & 64.8 & 106 & 35.2 \\
\hline 2010 & 206 & 63.9 & 116 & 36.1 \\
\hline 2011 & 225 & 66.9 & 111 & 33.1 \\
\hline 2012 & 225 & 63.1 & 132 & 36.9 \\
\hline 2013 & 212 & 60.1 & 141 & 39.9 \\
\hline 2014 & 201 & 56.4 & 156 & 43.6 \\
\hline 2015 & 216 & 58.1 & 156 & 41.9 \\
\hline 2016 & 215 & 55.6 & 171 & 44.4 \\
\hline 2017 & 220 & 53.6 & 190 & 46.4 \\
\hline 2018 & 239 & 54.4 & 200 & 45.6 \\
\hline 2019 & 229 & 52.2 & 210 & 47.8 \\
\hline 2020 & 186 & 46.7 & 212 & 53.3 \\
\hline
\end{tabular}

The data in the table confirm the hypothesis that the export and domestic consumption of coal in Russia developed in different ways, under the influence of different patterns. Domestic consumption remained fairly stable, especially if we exclude the abnormal 2020. But even in general, for the period 2001-2020, the standard deviation of domestic consumption indicators was 12 million tons, and the coefficient of variation was $5.66 \%$. Distribution asymmetry was insignificant. The dynamics of domestic coal consumption varies very little. It depends on the air temperature in winter and the volume of metal smelting, but does not change radically.

Therefore, to predict domestic coal consumption, the confidence interval of the general average and the marginal error can be used. Calculations showed that the standard error of 
the mean is 2.80 million tons; the marginal error is 6.82 million tons. Thus, the confidence interval of the average 215.95 million tons is $(215.95-6.821 ; 215.95+6.821)=(209.129$; 222.771). Therefore, the optimistic scenario of coal production in Russia for the next 10 years is about 225 million tons, the pessimistic one - about 210 million tons.

It is somewhat more difficult to forecast coal exports. On the one hand, it was constantly growing (except for 2008 and 2011), even in the crisis year of 2020, Russia was able to increase its export supplies of coal. For the first time, more than half of the coal mined was shipped for export. On the other hand, European countries remain an important direction of Russian coal exports (about 55\%), which are striving to completely abandon the use of steam coal by 2030 or a little later. Therefore, in the forecast, the authors proceeded from the following prerequisites.

1. Export of coal to Europe will decrease monotonically from the current level of about 117 million tons to 17-18 million tons (which is explained by the impossibility of replacing coking coal); the rate of decline will be even.

2. The supply of coal for export to the Asia-Pacific region will grow in line with the changing energy needs of the respective countries. They will peak by 2030, after which they will begin to decline.

Calculations have shown that the dynamics of Russian coal supplies to the Asia-Pacific region can be correctly described by the linear trend equation $Y=7.785 t+34.44$. It has a fairly low approximation error, high accuracy of fitting, statistically significant according to Fisher's and Student's criteria, autocorrelation and heteroscedasticity are not observed. All this allows us to build the following forecast of coal production in Russia in the period 2021-2030 (Table 4). Note that the change in warehouse balances is assumed to be negligible.

Table 4. Forecast of coal production in Russia in 2021-2030, million tons.

\begin{tabular}{|c|c|c|c|c|c|c|}
\hline & \multicolumn{2}{|c|}{ Domestic consumption } & \multirow{2}{*}{$\begin{array}{c}\text { Exports } \\
\text { westward }\end{array}$} & $\begin{array}{c}\text { Exports to Asia- } \\
\text { Pacific countries }\end{array}$ & \multicolumn{2}{|c|}{ Total production } \\
\cline { 7 - 8 } & Minimum & Maximum & & Minimum & Maximum \\
\hline 2021 & 210 & 225 & 106 & 120 & 436 & 451 \\
\hline 2022 & 210 & 225 & 95 & 127 & 432 & 447 \\
\hline 2023 & 210 & 225 & 84 & 134 & 428 & 443 \\
\hline 2024 & 210 & 225 & 73 & 142 & 425 & 440 \\
\hline 2025 & 210 & 225 & 62 & 150 & 422 & 437 \\
\hline 2026 & 210 & 225 & 51 & 159 & 420 & 435 \\
\hline 2027 & 210 & 225 & 42 & 166 & 418 & 433 \\
\hline 2028 & 210 & 225 & 33 & 174 & 417 & 432 \\
\hline 2029 & 210 & 225 & 24 & 182 & 416 & 431 \\
\hline 2030 & 210 & 225 & 18 & 190 & 418 & 433 \\
\hline
\end{tabular}

The obtained forecast estimates are in better agreement with the actual increase in production for the first 9 months of 2021 . At the same time, the production forecast by 2030 is significantly lower than when using hyperbole. In 2021, production is expected to 
increase at the level of 35-45 million tons, due to the post-crisis economic recovery. Then the dynamics of coal production will slow down due to the withdrawal of coal from the markets of Western Europe, where coal-fired power plants will be gradually closed. The growth of exports to the countries of the Asia-Pacific region will not be able to compensate for the drop in sales in the western direction.

Therefore, in 2025-2030, the volume of coal production in Russia will be about 420 million tons, which is below the maximum values of 2018-2019. Decarbonization of the global economy will have a significant impact on coal production in Russia. At the same time, the presented forecast does not imply hard-to-predict external shocks, for example, a faster transition of the Asia-Pacific countries to carbon neutrality or a drop in domestic demand for coal. In this case, the drop in production may turn out to be more severe.

\section{Conclusions}

The transition to carbon neutrality of the Western European economy will have serious negative consequences for the coal industry in Russia, since it developed in 2000-2020 due to the growth of exports. The forecast of coal production in Russia during the active transition to carbon neutrality should take into account the uneven dynamics of different types of coal use. During the period 2000-2020, coal production in Russia grew rapidly and almost monotonously. Even the 2009 crisis resulted in only a relatively small recession. In subsequent years, the volume of production sharply exceeded the pre-crisis level.

The dynamics of coal production in Russia over this period is poorly described by any trend equations. Therefore, the trend equations are impractical to use for forecasting. Depending on the shape, they are either statistically insignificant or have autocorrelation. The dynamics of coal production in Russia is described somewhat well by hyperbole. However, there is little historical data for its construction. According to the production forecast based on the extrapolation of the hyperbole trend, by 2025 coal production in Russia should be about 430 million tons, by 2030 - about 460-470 million tons.

This is close to the pessimistic mining scenario contained in government documents on the development of the Russian coal industry. But many Russian researchers and experts consider such estimates to be overestimated. In addition, the hyperbole-based forecast does not agree well with actual production data for the first 9 months of 2021. The use of exponential smoothing (Brown's model) also does not allow predicting production dynamics correctly. The study confirmed the hypothesis of the need for a differentiated prognosis.

The first component of mining is domestic consumption. The analysis showed that it is very stable (about 210-225 million tons), fluctuations mainly depend on the temperature regime. Therefore, the maximum (210 million tons) and minimum scenarios of production (225 million tons) of coal in Russia for domestic consumption have been adopted. It is considered constant, which is in good agreement with the data for 2000-2020. The second component is exports to the west. It is assessed on the basis of the premise of gradual cessation of steam coal imports by European countries. By 2030, it should drop to 15-20 million tons, which is consistent with the plans of the European Union countries to close coal-fired power plants. The third component is the export of coal to the countries of the Asia-Pacific region. The forecast is based on the fact that the peak in coal consumption will be passed in 2030. The dynamics of coal exports from Russia to the east is well described by the linear trend equation. In accordance with it, exports can increase from 120 million tons to 190 million tons, after which they will begin to gradually decline.

Thus, by 2030, Russia is expected to produce about 420-434 million tons of coal annually, of which about $50 \%$ will be consumed domestically, and about $40-45 \%$ will be supplied to the countries of the Asia-Pacific region. This forecast is worse than the 
pessimistic scenario for the development of the country's coal industry, which was previously predicted by the Russian Government. Therefore, the leading coal mining regions of Russia need to use the next 5-10 years to immediately diversify the economy

\section{Acknowledgment}

The work was carried out at the Centre for Shared Use of Scientific Equipment of the Kemerovo State University, created with the funds of the federal target program "Research and Development in Priority Areas of Development of the Scientific and Technological Complex of Russia for 2014-2020" (The competition was organized by the Ministry of Science and Higher Education of the Russian Federation).

\section{References}

1. A. Burkea, S. Fishel, Earth System Governance, 3 (2020)

2. S. Ladage, M. Blumenberg, D. Franke, A. Bahr, R. Lutz, S. Schmidt, Scientific Reports, 11 (2021)

3. O. Garanina, Russian Foreign Economic Journal, 25 (4) (2021)

4. D. Lugo-Morin, World, 2 (2) (2021)

5. M. Jakob, J. Steckel, F. Jotzo et al., Nature Climate Change, 10 (8) (2020)

6. D. Jie, X. Xu, F. Gao, Energy, 220 (2021)

7. G. He, J. Lin, Y. Zhang, One earth, 3 (2) (2020)

8. J. Baran, A. Szpor, J. Witajewski-Baltvilks, Energy Policy, 147 (1) (2020)

9. N. Johnson, V. Krey, D. McCollum, S. Rao, K. Riahi, J. Rogelj, Technological Forecasting and Social Change, 90 (1) (2015)

10. H. Xiao, W. Zhao, Y. Shan, D. Guan, Scientific Data, 8 (2021)

11. L. Plakitkina, E3S Web of Conferences: Energy-2021, 209 (2020)

12. G. Cherdantsev, T. Thurner, International Journal of Oil Gas and Coal Technology, 16 (4) (2017)

13. R. Finkelman, A. Wolfe, M. Hendryx, Energy Geoscience, 2 (2) (2021)

14. X. Tabachkova, S. Prosekov, N. Sokolinskaya, International Journal of Energy Economics and Policy, 10 (3) (2020) 